\title{
Puberty Suppression in a Gender-Dysphoric Adolescent: A 22-Year Follow-Up
}

\author{
Peggy T. Cohen-Kettenis - Sebastiaan E. E. Schagen • \\ Thomas D. Steensma • Annelou L. C. de Vries • \\ Henriette A. Delemarre-van de Waal
}

Received: 22 March 2010/Revised: 14 February 2011 / Accepted: 16 February 2011 / Published online: 19 April 2011

(C) The Author(s) 2011. This article is published with open access at Springerlink.com

\begin{abstract}
Puberty suppression by means of gonadotropin releasing hormone $(\mathrm{GnRH})$ analogs is considered a diagnostic aid in gender dysphoric adolescents. However, there are also concerns about potential risks, such as poor outcome or post-surgical regret, adverse effects on metabolic and endocrine status, impaired increment of bone mass, and interference with brain development. This case report is on a 22-year follow-up of a female-to-male transsexual, treated with GnRH analogs at 13 years of age and considered eligible for androgen treatment at age 17 , and who had gender reassignment surgery at 20 and 22 years of age. At followup, he indicated no regrets about his treatment. He was functioning well psychologically, intellectually, and socially; however, he experienced some feelings of sadness about choices he had made in a long-lasting intimate relationship. There were no clinical signs of a negative impact on brain development. He was physically in good health, and metabolic and endocrine parameters were within reference ranges. Bone mineral density was within the normal range for both sexes. His final height was short as compared to Dutch males; however, his body proportions were within normal range. This first report on long-term effects of puberty suppression suggests that negative side effects are limited and that it can be a useful additional tool in the diagnosis and treatment of gender dysphoric adolescents.
\end{abstract}

P. T. Cohen-Kettenis $(\bowtie) \cdot$ T. D. Steensma

Department of Medical Psychology and Medical Social Work, VU

University Medical Center, P.O. Box 7057, 1007 MB Amsterdam,

The Netherlands

e-mail: PT.Cohen-Kettenis@vumc.nl

S. E. E. Schagen - H. A. Delemarre-van de Waal

Department of Pediatrics, Leiden University Medical Center, Leiden, The Netherlands

A. L. C. de Vries

Department of Child and Adolescent Psychiatry, VU University

Medical Center, Amsterdam, The Netherlands
Keywords Gender identity disorder · Gender dysphoria . Transsexualism $\cdot$ Puberty suppression $\cdot$ Hormone treatment

\section{Introduction}

In 1998, a case study was published describing the use of a gonadotropin releasing hormone $(\mathrm{GnRH})$ analog to suppress puberty of a 13-year-old gender-dysphoric girl (Cohen-Kettenis \& van Goozen, 1998). At age 16, she was referred to a gender identity clinic where a diagnosis of gender identity disorder (GID) was made. She was considered eligible for androgen treatment at age 17, but chose to delay the therapy and social transitioning until she was 18 years old, because she first wanted to finish high school. Subsequently, she had gender reassignment surgery. This case illustrated that puberty suppression may be useful as an additional tool in the diagnosis and treatment of young gender dysphoric adolescents and that, for certain adolescents with a life-long consistent and extreme GID, it may be a physically and psychologically beneficial way to intervene.

Since this first case, GnRH analog prescription has been introduced as a part of an extended diagnostic phase on a more regular basis at the Dutch clinic where she had been treated. The way it was used in the diagnostic protocol has been described in detail elsewhere (Cohen-Kettenis \& Pfäfflin, 2003; Cohen-Kettenis \& Delemarre-van de Waal, 2006). In the last decade, puberty suppression has become part of the gender reassignment procedure in a number of clinics in European countries, Australia, Canada, and the U.S.

As has been argued previously, puberty suppression in gender dysphoric adolescents has a number of advantages (CohenKettenis, Delemarre-van de Waal, \& Gooren, 2008; Wren, 2000).

First, it may relieve the suffering that stems from a discrepancy between one's assigned and experienced/expressed gender, which can adversely affect one's social development and school career. Second, adolescents and mental health professionals 
"buy" time, which enables them to explore the adolescents' gender identity development and their desire for gender reassignment. Third, GnRH analog treated adolescents with persisting GID will, as adults, have fewer problems in passing in the new gender than untreated adolescents, which may contribute to better adjustment (Nuttbrock et al., 2010; Ross \& Need, 1989). Fourth, pubertal suppression makes certain forms of surgery redundant or less invasive. Fifth, unfavorable postoperative outcome seems to be associated with a late rather than an early start of gender reassignment (for reviews, see Cohen-Kettenis \& Gooren, 1999; Pfäfflin \& Junge, 1992). Sixth, youth without access to this treatment may try to find illicit sources of medication (e.g., the Internet).

Resistance to pubertal suppression also exists. Some consider it impossible to make a definitive diagnosis of GID in adolescence, because they believe that gender identity may still be fluctuating during this developmental phase (Korte et al., 2008; Viner, Brain, Carmichael, \& Di Ceglie, 2005). However, GID in adolescence appears to be highly persistent. At the Dutch gender identity clinic, none of the adolescents diagnosed with GID and treated with GnRH analogs refrained from further treatment procedures or regretted gender reassignment. Those who could not start treatment immediately after completion of the diagnostic procedure because of serious risk factors did not refrain from pursuing gender reassignment later. They usually started treatment after the other issues had been addressed, which was, in some cases, in early adulthood.

Another important point of criticism concerns the physical consequences of GnRH analogs on the development of bone mass, growth, and brain development. The first data of a Dutch cohort of adolescents who had been treated with GnRH analogs suggest that, after an initial slowing in bone accretion, it significantly caught up after the commencement of cross-sex steroid hormone treatment (Delemarre-van de Waal \& CohenKettenis, 2006). Body proportions, as measured by sitting height and sitting-height/height ratio, remained in the normal range. With regard to height, for both genders, stature could be influenced hormonally to become more in the range of the desired sex (Delemarre-van de Waal \& Cohen-Kettenis, 2006).

Since most of the adolescents who were treated with $\mathrm{GnRH}$ analogs are still in their early $20 \mathrm{~s}$, psychological and physical long-term effects of puberty suppression are not known. This report is the first very long-term follow-up (22 years) of a natal female, now 35 years old, who underwent pubertal suppression and subsequent gender reassignment. He read the report and provided us with a letter of consent to publish it.

\section{Case Report}

First Follow-Up: Psychosocial Information

In the 1998 report on the treatment of B, he was 20 years old. B had been a child with a classical gender dysphoric development and fulfilled the current criteria for GnRH analog treatment eligibility. He was interviewed shortly after his legal gender change. This meant that he had had puberty suppression, cross-sex hormone treatment, a mastectomy, ovariectomy, and uterus extirpation. From his assessment during the diagnostic phase, he appeared to be an intelligent person $(\mathrm{IQ}=128)$ with excellent problem-solving capabilities with respect to emotional matters. Vulnerable aspects of his psychological functioning were his insecurity about himself and moderately depressed feelings. In all other areas, his scores on a broad range of measures were in the average range, as compared to Dutch normative samples. Shame concerning his transsexualism made him highly selective in his friendships and guarded in his contacts with new people. At the assessment, 1 year after his ovariectomy but prior to his metaidoioplasty, he no longer reported feelings of gender dysphoria. He had adjusted easily to the male role and expressed no doubts on the adequacy of his masculine behavior. After the development of his secondary male sex characteristics, nobody had ever approached him as a woman. He never felt any regrets about his decision and had never contemplated living as a girl again. Knowing what gender reassignment implied, he would do it all over again. B was happy with his life and did not feel lonely. He showed a significant pre-post treatment decrease in his feelings of inadequacy. At the time, he was attending medical school.

\section{First Follow-Up: Medical Information}

$\mathrm{B}$ attended the pediatric endocrinology clinic for the first time when he was age 13.7 years. His medical history was uneventful. Puberty had started 1-2 years previously, but menarche had not occurred. On physical examination, a healthy girl was seen with a height of $157.3 \mathrm{~cm}$ and a Tanner pubertal stage of B3, P3. Bone age according to Tanner and Whitehouse was 13.5 years. Target height, as a female, was estimated at $171 \mathrm{~cm}$, based on the parental height. Puberty suppression was induced by the GnRH analog Triptorelin, in a dose of $3.75 \mathrm{mg}$ every 4 weeks intramuscularly. On this dosage, B steadily kept on growing.

At age 18.6 years, his height was $165.8 \mathrm{~cm}$. Induction of male puberty and accompanying secondary male sex characteristics was initiated by administration of $100 \mathrm{mg}$ testosterone-ester mixture intramuscularly every 2 weeks. This was, after 6 months, increased to $250 \mathrm{mg}$ testosterone-ester mixture, every 2-3 weeks intramuscularly. At the start of the androgen treatment, the Triptorelin treatment was discontinued.

When B was 20 years old, he had a subcutaneous mastectomy by way of an infra-areolar approach, a few months later followed by a hysterectomy and gonadectomy. Two years later, metaidoioplasty and testes implantation were performed.

Second Follow-Up: Psychosocial Information

Fifteen years after the first interview and testing session, at age 35 , B was seen again at the clinic. He lived on his own and he 
worked as a family doctor in private practice with two colleagues. All family members knew about his transitioning as did some of his friends. He was very satisfied about his circle of friends and had never been treated negatively because of his transsexualism.

B was still satisfied about his (minor) breast surgery, his ovariectomy, and his hysterectomy, but no longer about the metaidoioplasty he underwent one year after the first follow-up session. He did not like its size and shape and he could hardly urinate in a standing position. He was able to have orgasms, but he could not have sexual intercourse. Because of his desire to have more convincingly male appearing external genitals and his wish to be able urinate in a standing position, he considered having a phalloplasty. Despite his good looks and very masculine appearance, he had not had many steady girlfriends, which may have resulted from the guardedness he already had as an adolescent. At age 29, he had a serious relationship with a woman, which lasted for 5 years. However, he chose not to live together when the opportunity to do so arose. After his choice to continue living apart, his girlfriend ended the relationship, a few months before his interview at the clinic. This made him very much regret his lack of commitment. B considered it likely that his need to distance himself from her had been related to his shame about his genital appearance and his feelings of inadequacy in sexual matters. Additional factors, such as serious illness of his father and a suicide among his sisters' in-laws, made him rather sad at the time of the interview. Although his psychoneuroticism score on the Symptom Checklist-90 (Arrindell \& Ettema, 2003) was in the normal range, his depression subscore was high, indicating depressed feelings. However, on the Beck Depression Inventory, he scored in the "minimal range" (van der Does, 2002), indicating that he did not fulfill criteria for clinical depression. On the Adult Self-Report, assessing adaptive functioning and problems in adults aged 18-59 years (Achenbach \& Rescorla, 2003), all his scores were in the normal range.

It seems, therefore, that B functioned well in most aspects of life, but that he was still struggling with the question, how to handle the dissatisfaction and shame about his genital appearance.
Second Follow-Up: Medical Information

At age 35, on physical examination, we saw a healthy and well virilized person. Blood pressure was $120 / 85 \mathrm{mmHg}$, final height was $169.5 \mathrm{~cm}$ and weight was $73 \mathrm{~kg}$, which resulted in a body mass index (BMI) of $25.4 \mathrm{~kg} / \mathrm{m}^{2}$. Sitting height was $88 \mathrm{~cm}$. Skull circumference was $55.5 \mathrm{~cm}$. For a comparison of his anthropometrical measurements to the normal reference values of Dutch males and females, see Table 1.

\section{Test Results}

A fasting venous blood sample was drawn. General health markers, like hematological parameters ( $\mathrm{Hb}$, ht, erythrocytes), renal function, and liver enzymes, were all within the normal reference value ranges. His lipid profile showed a total cholesterol level of $228.3 \mathrm{mg} / \mathrm{dl}$ ( $<251.5 \mathrm{mg} / \mathrm{dl})$, LDL-cholesterol $154.8 \mathrm{mg} /$ dl $(<193.5 \mathrm{mg} / \mathrm{dl})$, HDL-cholesterol $55.0 \mathrm{mg} / \mathrm{dl}(>34.8 \mathrm{mg} / \mathrm{dl})$, and triglycerides $97.4 \mathrm{mg} / \mathrm{dl}(<177 \mathrm{mg} / \mathrm{dl})$. His glucose value was $97.3 \mathrm{mg} / \mathrm{dl}(<144.1 \mathrm{mmol} / \mathrm{l})$ with an insulin level of $21 \mathrm{pmol} / 1$ (12-96 pmol/l for a fasting sample). His HbA1c was 5.4\% (4.3$6.1 \%$ ). These values were in the normal range.

With respect to the gonadal axis, a normal-low serum testosterone level of $236.6 \mathrm{ng} / \mathrm{dl}$ (231-866 ng/dl) was found. This relatively low level was probably due to the fact that the blood sample was taken just before the next testosterone-ester mixture injection. Gonadotropins were elevated as a consequence of the gonadectomy. LH and FSH were $16 \mathrm{U} / 1$ and $50 \mathrm{U} / 1$, respectively. Additionally determined endocrine parameters, such as thyroid and adrenal function, were all within normal reference ranges.

With respect to bone mineral density (BMD), a dual energy X-ray absorptiometry (DEXA) scan was performed to determine B's BMD in the lumbar spine, the non-dominant hip, and (further) total body. The observed values were related to the bone peak mass for white females and for white males, resulting in T-scores. For all values, the $z$-score was determined as well (see Table 2).

Table 1 B's anthropometrical measurements at the time of his last visit to our outpatient clinic (age 35) compared to Dutch reference values for both sexes

\begin{tabular}{llcccc}
\hline & $B$ & SD females & P50 females & SD males & P50 males \\
\hline Height $(\mathrm{cm})$ & 169.5 & -0.16 & 170.56 & -2.03 & 183.86 \\
Weight $(\mathrm{kg})$ & 73 & 0.95 & 63.85 & -0.24 & 75.28 \\
Sitting height $(\mathrm{cm})$ & 88 & -0.47 & 89.63 & -1.94 & 94.65 \\
Sitting height/height ratio & 0.519 & -0.47 & 0.5260 & 0.02 & 0.5130 \\
Skull circumference $(\mathrm{cm})$ & 55.5 & 0.13 & 55.29 & -1.32 & 57.82 \\
BMI $\left(\mathrm{kg} / \mathrm{m}^{2)}\right.$ & 25.4 & 1.93 & 22.90 & 1.90 & 22.11 \\
\hline
\end{tabular}

$S D$ standard deviation, $P 50$ 50th percentile 
Table 2 Bone mineral density values of the regions of interest compared to the reference values of both sexes

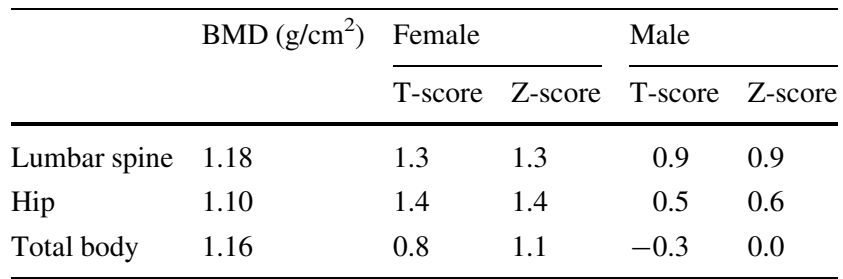

\section{Discussion}

The case of B is the first in the literature to show the long-term results of puberty suppression and subsequent hormonal and surgical intervention in a consistently gender dysphoric youth. Suppression of puberty in adolescents should be done only after careful diagnostic work by specialists in the field. Giving informed consent is a crucial aspect of the procedure. In order to give valid consent, the adolescent should have, as completely as possible, information about known and unknown aspects of the treatment. In the case of $\mathrm{B}$, it was not possible to give the 13 year adolescent much information on the long-term effects of GnRH analog treatment in physically healthy young people. Yet, B was certain that he did not want any further pubertal development and very deliberately decided to start with the GnRH analogs. For a number of years, still living in the female role, B took the opportunity to figure out whether he truly wanted to have gender reassignment, knowing that this would not be an easy life. Although he tended to be embarrassed about his gender dysphoria, especially in the beginning of the process, he has always been quite clear about his feeling that he could not live further as a girl. Twenty-two years after this decision, he still is convinced that his choice to live as a man was the right one.

The concern of many clinicians that halting puberty for a number of years would involve unacceptable health risks turned out not to be true for B. All observed anthropometric measurements were within the normal range (50th percentile $\pm 2 \mathrm{SD}$ ) for biological females. Also, B's final height was within the target height range for females. When compared to natal males, however, B's final height was just below -2 SD. In all other respects, B's anthropometric values were in the low-normal male range. It is noteworthy to realize that the normal values we have used came from Dutch population studies. As B is half Italian, they could also be compared to values for inhabitants from Italy, which deviate from those of the Dutch normal population. The 50th percentile values for height for the Italian population are $163.2 \mathrm{~cm}$ and $176.9 \mathrm{~cm}$ for females and males, respectively (Cacciari et al., 2002). As B's sitting height/height ratio is near the 50th percentile for both sexes, B's body proportion is within the normal range. Blood tests showed increased serum levels of FSH and LH, which was due to his gonadectomy. B's lipid profile did not deviate from the normal reference values and the
BMD measurements showed values well above the 50th percentile for biological females. Compared to reference values for white males, his BMD values were around the 50th percentile.

Although B would have liked to be taller, we did not find unfavorable medical outcomes. Therefore, the fear that GnRH analog treatment will result in poor long-term outcome was not supported in this case. Nonetheless, long-term follow-up studies on larger cohorts of transgender adults treated with GnRH analogs are needed to support this finding.

Although gender reassignment is highly effective in relieving gender dysphoria (Cohen-Kettenis \& Gooren, 1999; Gijs \& Brewaeys, 2007; Pfäfflin \& Junge, 1992), it is no panacea. Especially in the area of intimate relationships, it may remain difficult to find a suitable partner and overcome one's own barriers, as is shown in the case of B.

Pubertal suppression, however, averts the despair of gender dysphoric adolescents because of their physical changes and it may contribute to more self-confidence when socially interacting in adolescence and adulthood. On a day-to-day basis, B did not have to explain himself or defend his choices. He was not harassed or stigmatized. The case of $\mathrm{B}$ gives hope that negative side effects of puberty suppression are limited, although the results will have to be confirmed in further studies. With regard to the psychological functioning of puberty suppressed and subsequently gender reassigned individuals, a relatively favorable outcome (at least one year post-surgery) was also recently reported (de Vries, 2010). This and B's second follow-up again illustrate that puberty suppression can be a useful additional tool in the diagnosis and treatment of gender dysphoric adolescents. This view is supported in the recently published guidelines of the Endocrine Society on the treatment of transsexual persons (Hembree et al., 2009).

Open Access This article is distributed under the terms of the Creative Commons Attribution Noncommercial License which permits any noncommercial use, distribution, and reproduction in any medium, provided the original author(s) and source are credited.

\section{References}

Achenbach, T. M., \& Rescorla, L. A. (2003). Manual for ASEBA adult forms \& profiles. Burlington, VT: University of Vermont Research Center for Children, Youth, and Families.

Arrindell, W. A., \& Ettema, J. H. M. (2003). SCL-90 Symptom checklist. Amsterdam: Pearson Assessment and Information B.V.

Cacciari, E., Milani, S., Balsamo, A., Dammacco, F., De Luca, F., Chiarelli, F., et al. (2002). Italian cross-sectional growth charts for height, weight and BMI (6-20y). European Journal of Clinical Nutrition, 56, 171-180.

Cohen-Kettenis, P. T., Delemarre-van de Waal, H. A., \& Gooren, L. J. (2008). The treatment of transsexual adolescents: Changing insights. Journal of Sexual Medicine, 5, 1892-1897.

Cohen-Kettenis, P. T., \& Gooren, L. J. (1999). Transsexualism: A review of etiology, diagnosis and treatment. Journal of Psychosomatic Research, 46, 315-333. 
Cohen-Kettenis, P. T., \& Pfafflin, F. (2003). Transgenderism and intersexuality in childhood and adolescence: Making choices. Thousand Oaks, CA: Sage Publications.

Cohen-Kettenis, P. T., \& van Goozen, S. H. (1998). Pubertal delay as an aid in diagnosis and treatment of a transsexual adolescent. European Child and Adolescent Psychiatry, 7, 246-248.

de Vries, A. L. C. (2010). Gender dysphoria in adolescents: Mental health and treatment evaluation. Doctoral dissertation, VU University, Amsterdam.

de Vries, A. L. C., Cohen-Kettenis, P. T., \& Delemarre-van de Waal, H. A. (2006). Caring for transgender adolescents in BC: Suggested guidelines. Clinical management of gender dysphoria in adolescents. International Journal of Transgenderism, 9, 83-94.

Delemarre-van de Waal, H. A., \& Cohen-Kettenis, P. T. (2006). Clinical management of gender identity disorder in adolescents: A protocol on psychological and paediatric endocrinology aspects. European Journal of Endocrinology, 155, 131-137.

Gijs, L., \& Brewaeys, A. (2007). Surgical treatment of gender dysphoria in adults and adolescents: Recent developments, effectiveness, and challenges. Annual Review of Sex Research, 18, 178-224.

Hembree, W. C., Cohen-Kettenis, P. T., Delemarre-van de Waal, H. A., Gooren, L. J., Meyer, W. J., Spack, N. P., et al. (2009). Endocrine treatment of transsexual persons: An Endocrine Society Clinical Practice Guideline. Journal of Clinical Endocrinology and Metabolism, 94, 3132-3154.
Korte, A., Lehmkuhl, U., Goecker, D., Beier, K. M., Krude, H., \& Gruters-Kieslich, A. (2008). Gender identity disorders in childhood and adolescence: Currently debated concepts and treatment strategies. Deutsches Ärzteblatt International, 105, 834-841.

Nuttbrock, L., Hwahng, S., Bockting, W., Rosenblum, A., Mason, M., Macri, M., et al. (2010). Psychiatric impact of gender-related abuse across the life course of male-to-female transgender persons. Journal of Sex Research, 47, 12-23.

Pfäfflin, F., \& Junge, A. (1992). Nachuntersuchungen nach Geslechtsumwandlung. Eine kommentierte Literatübersicht 1961-1991. In F. Pfäfflin \& A. Junge (Eds.), Geslechtsumwandlung. Anhandlungen zur Transsexualität (pp. 149-457). Stuttgart: Schattauer.

Ross, M. W., \& Need, J. A. (1989). Effects of adequacy of gender reassignment surgery on psychological adjustment: A follow-up of fourteen male-to-female patients. Archives of Sexual Behavior, 18, 145153.

van der Does, A. J. W. (2002). BDI-II-NL | Beck depression inventory (2nd ed.). Amsterdam: Pearson Assessment and Information B.V.

Viner, R. M., Brain, C., Carmichael, P., \& Di Ceglie, D. (2005). Sex on the brain: Dilemmas in the endocrine management of children and adolescents with gender identity disorder. Archives of Disease in Childhood, 90, A78.

Wren, B. (2000). Early physical intervention for young people with atypical gender identity development. Clinical Child Psychology and Psychiatry, 5, 220-231. 